\title{
Primary gas discharge transducer and its application
}

\author{
Gennadii Smirnov, ${ }^{1, *}$, and Aleksey Kovalsky ${ }^{1}$ \\ ${ }^{1}$ Tomsk State University of Control Systems and Radioelectronics, 634050 Tomsk, Russia
}

\begin{abstract}
The aim of this study is to develop a high-speed fault transducer and, based on it, to create an automated system for monitoring and repairing faulty insulation of winding wires in electrical equipment. The fault transducer under development is based on a gas discharge process that occurs between a high-voltage electrode and a grounded wire conductor in a damaged insulation segment. Oscillographic measurements show that there is a complex signal that appears on the fault transducer when a damaged insulation segment is passed through it. The basic patterns of electrodeposition of dielectric films onto metals were determined. The conditions of this process were optimized. The features of the above-mentioned signal that can be used to monitor the number of faults and lengths of damaged segments, as well as the features of the deposition of dielectric films onto metals were justified. Based on these features, a faulty wire insulation repair process was developed and can be controlled.
\end{abstract}

\section{Introduction}

At present, fault monitoring of enamel wire insulation in Russia is regulated by GOST IEC 60851-5-2011. According to this document, the integrity of insulation is expressed in terms of the number of point faults detected by an electrical testing device per wire of a certain length. Point faults for wires with a rated conductor diameter of up to and including $0.050 \mathrm{~mm}$ are identified at a low voltage using a transducer consisting of two felt plates immersed in a solution of aqueous sodium sulfate $\mathrm{Na}_{2} \mathrm{SO}_{4}(30 \mathrm{~g} / \mathrm{L})$, between which a controlled wire is passed at a rate of $(275 \pm 25) \mathrm{mm} / \mathrm{s}$. A test DC voltage $(50 \pm 3) \mathrm{V}$ is applied between the wire conductor and the solution connected to the electrical circuit. Point faults are recorded by an appropriate relay with a counter. A disadvantage of this monitoring technique is low sensitivity of the transducer and contamination of the insulation with electrolyte during the monitoring. This makes it impossible to test all wires completely, and they are tested selectively on individual segments and from different coils.

For wires with a conductor diameter of 0.050 to $0.25 \mathrm{~mm}$, a transducer electrode made in the form of two rollers is used. A controlled wire is passed through the transducer formed by four rollers, two of which are guides and the other two are electrodes. For wires with a diameter of 0.25 to $1.60 \mathrm{~mm}$, this transducer cannot be used. Instead of it, one high-voltage roller electrode of a larger diameter is used. In this monitoring procedure, the wire is

\footnotetext{
*Corresponding author: smirnov@main.tusur.ru
} 
repeatedly bent. This leads to high mechanical stresses on the wire insulation on the electrode side, which not only weakens mechanical and electrical strength of the insulation in a controlled wire, but also causes additional faults in the insulation.

The fault monitoring techniques described above are not able to determine the length of damaged segments, another indicator of insulation failure which is equally important as the number of faults.

Another disadvantage of the monitoring technique described in GOST IEC 60851-52011 is that it is applied selectively to a segment of the wire from a coil that has been randomly chosen from a batch and, therefore, leaves the bulk of the wire on the chosen coil untested. The same applies to other coils in the batch that have not been chosen for random inspection, thereby reducing its reliability.

Due to the low quality of enamel insulation, electric motors may fail at any time [1-7], potentially leading to an accident. Rejection of faulty wires and their use in products lead to significant economic losses (since such expensive materials as enamel, wire, etc. are wasted) and unreasonable recycling costs.

The studies [8-11] are dedicated to this problem.

The aim of this study is to develop a high-speed fault transducer and, based on it, to create an automated system for monitoring and repairing faulty insulation of winding wires in electrical equipment.

\section{Research Materials and Methods}

The tests were performed in two stages. At the first stage, the gas discharge fault transducer was tested. The design of the transducer is justified in detail in $[12,13]$.

The transducer consists of two cylindrical electrodes that are contiguous to each other along the generatrix and mounted on axes through bearings. The bearing axes are fixed on movable levers (rockers) that allow roller electrodes to make vertical movements in synchrony with wire vibrations. Electrodes are pressed to each other by blade springs. Voltage is applied to electrodes through sliding contacts. For testing purpose, a controlled wire was passed through the above-mentioned electrodes pressed to each other. The signal generated on the transducer when a damaged segment of wire insulation was passed through it, was recorded with one oscilloscope beam from the low-voltage arm of the voltage divider connected to the transducer. The discharge current was measured on the limiting resistance in the discharge circuit of the transducer.

In order to repair faulty wire insulation, it was first necessary to develop a technique for applying an insulating film to a damaged segment. This task was solved at the second stage of the study. The second stage involved searching for and optimizing components that, when combined, would give electrophoretic properties to a PE-939 lacquer designed for enameling PETV grade wires with a temperature index of $140 \div 180^{\circ} \mathrm{C}$.

It was empirically found that, in case of the film-forming lacquer PE-939, electrophoresis occurs when using dioxane as a solvent and $1 \% \mathrm{NH}_{4} \mathrm{OH}$ as an electrolyte [14].

\section{Results}

A typical oscillogram of the signal from the transducer when passing a damaged segment of the wire insulation is shown in Figure 1. 


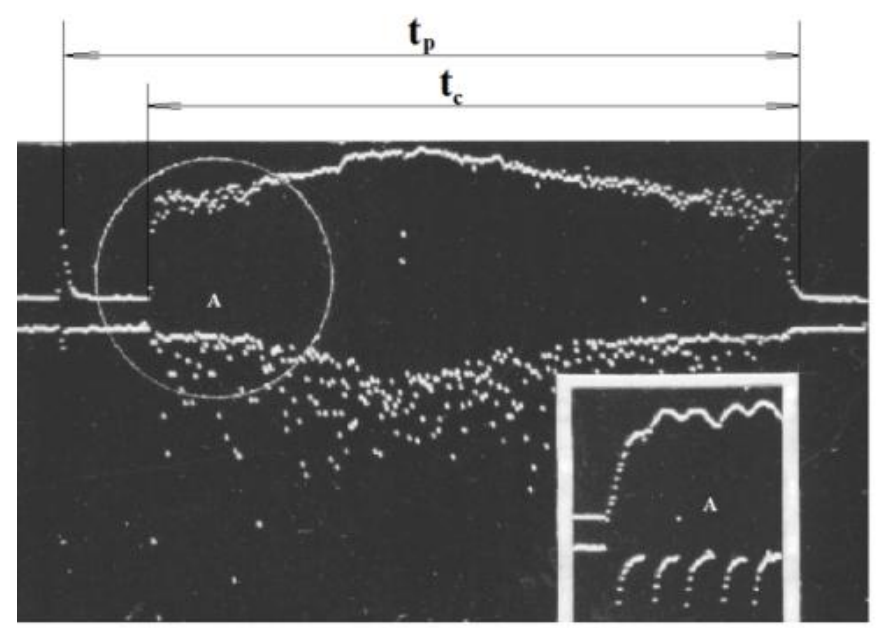

Fig. 1. A typical oscillogram from the fault transducer. $t_{p}$ is the total burning time of the discharge upon approaching the transducer and until leaving the transducer; $t_{c}$ is the burning time of the discharge between the transducer and the fault when the fault is just under the transducer; $A$ is the highlighted rising edge of the oscillogram shown on its lower part with a higher temporal resolution.

The oscillogram (Fig. 1) was taken at a negative potential $\mathrm{U}=-2 \mathrm{kV}$ on the electrode rollers relative to the grounded conductor at wire speed $\mathrm{V}=3.07 \mathrm{~m} / \mathrm{s}$. Two times are highlighted on the oscillogram: $t_{p}=4.1 \times 10^{-3} \mathrm{~s}$ and $t_{c}=3.5 \times 10^{-3} \mathrm{~s}$. The pattern of the oscillogram (Fig. 1) can be explained as follows.

The ignition of the corona discharge upon approaching a fault in the wire insulation can be explained as follows. When the fault is moved towards the transducer, the distance between them decreases and, due to this, the electric field strength increases. At a certain critical distance between the transducer and the fault and when the transducer voltage is equal to the initial corona onset voltage, a corona discharge is ignited in the damaged area.

When the fault approaches the transducer, the electric field in the fault area increases, avalanche processes become more intense, and the corona discharge is converted into spark discharge. The capacitance of the circuit begins to discharge and leads to a voltage drop across this gap. The electric field strength in the damaged area falls to a certain value. The current rise rate in the gap decreases and the discharge goes out.

In Figure 1, this process is represented by the first pulse on the current oscillogram. After extinction of the discharge, the capacitance of the discharge circuit begins to be charged from the power source. The voltage across the gap between the fault and the transducer increases. After the transducer voltage is restored to the initial value, spark reignition may not occur immediately. It occurs after a certain time $\Delta \mathrm{t}$, which varies significantly and depends on the wire speed, amplitude, period of transverse wire vibration, and many other factors. (On the oscillogram presented in Figure 1, $\Delta \mathrm{t}=\mathrm{t}_{\mathrm{p}}-\mathrm{t}_{\mathrm{c}}$ ).

Therefore, when the fault approaches the transducer and leaves it, the spark rate is unstable, and the value $\Delta \mathrm{t}$ varies significantly from fault to fault. When the transducer enters the transducer zone, the discharge stabilizes and, as the distance between the fault and the transducer decreases, subsequent spark ignitions occur at lower voltages than those upon approaching and leaving the fault. On the oscillogram, the residence time of the fault under the roller electrodes is indicated as $t_{c}$.

Estimates resulting from the experiments show that the optimal diameter of the transducer rollers should be in the range of 10 to $16 \mathrm{~mm}$. 
The second stage of the studies was aimed at optimizing components of the electrophoretic composition. Experiments were carried out using the complete factorial $\operatorname{design} 2^{\mathrm{k}}$.

The levels of variable factors are given in Table 1 where the following notations are introduced: $x_{1}=\left(n_{l^{-}} n_{1}^{0}\right) / 2 ; x_{2}=\left(n_{l^{-}} n_{2}^{0}\right) / 2 ; x_{1}, x_{2}$ are codes of concentrations of the PE-939 lacquer and liquid ammonia $1 \% \mathrm{NH}_{4} \mathrm{OH}$, respectively; $n_{l}, n_{2}$ are real concentrations of the PE-939 lacquer and liquid ammonia $1 \% \mathrm{NH} 4 \mathrm{OH}$, respectively; $n_{1}^{0}, n_{2}^{0}$ is the center of design determined by the following formulas: $n_{1}^{0}=\left(\mathrm{n}_{1 \max }-\mathrm{n}_{1 \min }\right) / 2 ; n_{2}^{0}=\left(\mathrm{n}_{2 \max }-\mathrm{n}_{2 \min }\right) / 2$; $\mathrm{n}_{1 \max }=390 \mathrm{ml} / \mathrm{L}, \mathrm{n}_{2 \max }=210 \mathrm{ml} / \mathrm{L}, \mathrm{n}_{1 \min }=290 \mathrm{ml} / \mathrm{L}, \mathrm{n}_{2 \min }=110 \mathrm{ml} / \mathrm{L}$ are maximum and minimum values of the selected factors used in the experiments, respectively; $\Delta \mathrm{n}_{1}, \Delta \mathrm{n}_{2}$ are the variability intervals of the factors determined by the formulas: $\Delta \mathrm{n}_{1=}\left(\mathrm{n}_{1 \max }+\mathrm{n}_{1 \min }\right) / 2$; $\Delta \mathrm{n}_{2=}\left(\mathrm{n}_{2 \max }+\mathrm{n}_{2 \min }\right) / 2$.

Table 1. Levels of variable factors.

\begin{tabular}{|l|l|l|l|l|l|l|}
\hline $\begin{array}{l}\text { Components of } \\
\text { electrophoretic } \\
\text { composition, } \mathrm{ml} / \mathrm{L}\end{array}$ & Designation & Coded & +1 & 0 & -1 & Variability \\
\cline { 2 - 7 } & Real & $\mathrm{x}_{1}$ & 390 & 340 & 290 & 50 \\
\hline Content of PE-939 & $\mathrm{n}_{1}$ & $\mathrm{x}_{2}$ & 210 & 160 & 110 & 50 \\
\hline Content of $1 \% \mathrm{NH} 4 \mathrm{OH}$ & $\mathrm{n}_{2}$ & \multicolumn{2}{|l|}{} \\
\hline
\end{tabular}

After statistical processing of the obtained results and regression analysis, the following adequate regression equation was obtained:

$$
U_{\text {forward }}=-5.4375-0.26 x_{1}-0.24 x_{2}+0.3125 x_{1} x_{2}-1.973 x_{1}^{2}-1.095 x_{2}^{2}
$$

After the transition to the full scale, by substituting $x_{1}$ and $x_{2}$ in equation (1) for their full-scale values, we obtain:

$$
U_{\text {forward }}=-59.49+0.247 n_{1}+0.272 n_{2}+0.000136 n_{1} n_{2}-0.00094 n_{1}^{2}-0.00044 n_{2}^{2}
$$

The planning matrix is given in Table 2 .

Table 2. Matrix planning and experimental results.

\begin{tabular}{|l|l|l|l|l|l|l|l|}
\hline $\begin{array}{l}\text { Experiment } \\
\text { No. }\end{array}$ & $\mathrm{X}_{1}$ & $\mathrm{X}_{2}$ & $\mathrm{U}_{1}$ & $\mathrm{U}_{1 \text { reverse }}$ & $\mathrm{U}_{2}$ & $\mathrm{U}_{2 \text { reverse }}$ & $\overline{\mathrm{U}}$ \\
\hline 1 & +1 & +1 & 2.28 & 2.16 & 2.76 & 2.9 & 2.53 \\
\hline 2 & -1 & +1 & 2.24 & 2.2 & 1.96 & 1.62 & 2.01 \\
\hline 3 & +1 & -1 & 2.88 & 1.84 & 1.76 & 2.04 & 2.11 \\
\hline 4 & -1 & -1 & 2.94 & 2.49 & 2.54 & 3.42 & 2.24 \\
\hline 5 & +1 & 0 & 3.22 & 2.82 & 2.84 & 2.28 & 2.79 \\
\hline 6 & 0 & +1 & 3.94 & 3.54 & 3.72 & 4.06 & 3.82 \\
\hline 7 & -1 & 0 & 4.4 & 3.92 & 3.9 & 4.36 & 4.14 \\
\hline 8 & 0 & -1 & 4.96 & 4.2 & 5.04 & 5.28 & 4.87 \\
\hline 9 & 0 & 0 & 2.8 & 2.16 & 2.94 & 2.2 & 2.85 \\
\hline
\end{tabular}


From equation (2), we can find the optimal ratio of the components $\mathrm{n}_{1 \mathrm{opt}}$ and $\mathrm{n}_{2 \mathrm{opt}}$

$$
\left\{\begin{array}{l}
\partial \mathrm{U} / \partial \mathrm{n}_{1}=0,247+0,000136 \mathrm{n}_{2}-2 \times 0,00094 \mathrm{n}_{1}=0 \\
\partial \mathrm{U} / \partial \mathrm{n}_{2}=0,272+0,000136 \mathrm{n}_{1}-2 \times 0,00044 \mathrm{n}_{2}=0
\end{array}\right.
$$

By solving the system (3), we obtain $\mathrm{n}_{\text {lopt }}=156.7 \mathrm{ml} / \mathrm{L} ; \mathrm{n}_{2 \text { опт }}=333.3 \mathrm{ml} / \mathrm{L}$. The dioxane concentration $\mathrm{n}_{3 \mathrm{opt}}=500 \mathrm{ml} / \mathrm{L}$.

The gas discharge fault transducer and electrodeposition of dielectric films were used as a basis for the wire insulation monitoring and repair system, which is described in detail in the patent [14].

\section{Conclusion}

The structure of the signal produced by the gas discharge fault transducer when passing a damaged segment of wire insulation through it was studied and presented in the paper. As shown, this signal has a complex structure. This structure was analyzed. It was shown how to single out a useful zone from this structure to exclude errors when calculating the number of faults and lengths of damaged segments. Concentrations of the components in the electrophoretic composition based on the PE-939 lacquer were justified and optimized. The developed primary fault transducer and the proposed electrodeposition technique for dielectric films can be used not only for designing automated wire repair system, but also for complete monitoring of wire insulations during enameling and production of windings. In addition, the composition and the electrodeposition technique can be used for other purposes, in particular, for wire enameling.

\section{References}

1. G.V. Smirnov Nadezhnost' izoljacii obmotok jelektrotehnicheskih izdelij [Reliability of coil insulation in electrical products] (Publishing House of the Tomsk State University, Tomsk, 1990) (in Russian)

2. T. Knych, A. Mamala, M. Jablonski, P. Uliasz, Wire Journal International, 45(1), 5561 (2012)

3. B. Gupta, Risk in surge testing of turn insulation in windings of rotating machines, in Electrical Insulation Conference and Electrical Manufacturing \& Coil Winding Technology Conference, 459- 462 (September 23-25, 2003)

4. J.P. Bellomo, P. Castelan, T. Lebey, IEEE Transactions on Dielectrics and Electrical Insulation, 6(1), 20-26 (1999)

5. F.R. Bohm, K. Nagel, H. Schindler, A new generation of wire enamel for the production of magnet wires with outstanding corona resistance, in Electrical Insulation Conference and Electrical Manufacturing \& Coil Winding Technology Conference, 109-113 (September 23-25, 2003)

6. A.H. Bonnett, G.C. Soukup, IEEE Transactions on Industry Applications, 28(4), 921937 (1992)

7. A.V. Andrianov, V.K. Andrianov, E.V. Bykov, Cables and Wires, 5(342) (2013), (in Russian)

8. M. Chapman, N. Frost, R. Bruetsch, Insulation systems for rotating low-voltage machines , IEEE International Symposium on Electrical Insulation, 257-260 (2008) 
9. D. Hwang, K. Lee, Y. Kim, I. Lee, T. Lim, D. Kim, Accessing the insulation characteristics for stator windings of low-voltage induction motors for adjustablespeed drive applications, IEEE Industry Application Conference, 432-438 (2003)

10. D. Fabiani, G.C. Montanari, A. Contin, Aging acceleration of insulating materials for electrical machine windings supplied by PWM in the presence and in the absence of partial discharges, IEEE 7th International Conference on Solid Dielectrics, 283-286 (2001)

11. S.R. Fenger, J. Campbell, IEEE Industry Applications Magazine, 9(4), 22-31 (2003)

12. G.V. Smirnov, D.G. Smirnov, Russian Journal of Nondestructive Testing, 8 (2016), (in Russian)

13. G.V. Smirnov, D.G. Smirnov, Datchik dlja nepreryvnogo kontrolja izoljacii provodov [Sensor for continuous monitoring of wire insulation], RF Patent No. 2597938 (20.09.2016) (in Russian)

14. G.V. Smirnov, D.G. Smirnov, Sposob kontrolja i remonta izoljacii provodov [Means for monitoring and repair of wire insulation], RF Patent No. 2506602 (10.02.2014) (in Russian) 